\title{
Pengaruh Faktor Geografi Terhadap Karakteristik Bambu Petung
}

\author{
Andromeda Dwi Laksono', Diah Tri Agustiningtyas ${ }^{2}$ \\ ' Teknik Material dan Metalurgi, Ilmu Kebumian dan Lingkungan, Institut Teknologi Kalimantan, Balikpapan. \\ Email : Andromeda@itk.ac.id \\ ${ }^{2}$ Teknik Material dan Metalurgi, Ilmu Kebumian dan Lingkungan, Institut Teknologi Kalimantan, Balikpapan. \\ Email : $\underline{06161017 @ \text { itk.ac.id }}$
}

\begin{abstract}
In this study was about a comparison of geographic factors towards the characterization of petung bamboo in Indonesia and the Philippines. Bamboo is one of the plants that has advantages in the field of technical materials based on developments in composite materials and is found in various regions. In general, bamboo has lignin and cellulose, where the morphology and nature of both bamboos are not the same from different countries. Therefore, material testing was carried out on each Indonesian and Filipino petung bamboo using material characterization testing methods. The process of Differential Scanning Calorimetry (DSC) was carried out to measure calorimetry with the yield of melting point in Philippine petung bamboo at $341^{\circ} \mathrm{C}$ which is lower than the melting point in Indonesian petung bamboo which is $354.34^{\circ} \mathrm{C}$. In this DSC test, quantitative and qualitative results were obtained in the form of phase changes, melting, and transition temperatures that occurred. Then an Energy Dispersive Spectrometer (EDS) was analyzed and the carbon content of cellulose and lignin was higher in Indonesian petung bamboo, respectively 65.29 wt.\% And $66.05 \mathrm{wt} . \%$. The morphology of bamboo shows that the fibers and matrices present in Philippine petung bamboo are denser than those of Indonesian petung bamboo. The highest peak value based on X-Ray Diffraction (XRD) is found in Philippine petung bamboo at $2 \theta$ of 34.49 and cubic phase.
\end{abstract}

Keywords: Petung bamboo, composite, lignin, cellulose, characterization

\begin{abstract}
Abstrak
Pada penelitian ini dilakukan perbandingan faktor geografi terhadap karakterisasi bambu petung Indonesia dan Filipina. Bambu merupakan salah satu tanaman yang memiliki kelebihan di bidang material teknik berdasarkan perkembangan pada material komposit dan banyak ditemukan di berbagai wilayah. Pada umumnya bambu memiliki lignin dan selulosa, dimana morfologi dan sifat dari kedua bambu tidak sama dari negara yang berbeda. Oleh karena itu, dilakukan pengujian material terhadap masing-masing bambu petung Indonesia dan Filipina dengan metode pengujian karakterisasi material. Proses Differential Scanning Calorimetry (DSC) dilakukan untuk mengukur kalorimetri dengan hasil titik leleh pada bambu petung Filipina sebesar $341^{\circ} \mathrm{C}$ dimana lebih rendah dibanding titik leleh pada bambu petung Indonesia yaitu $354,34^{\circ} \mathrm{C}$. Pada pengujian DSC ini didapatkan hasil kuantitatif dan kualitatif berupa perubahan fase, leleh, dan temperatur transisi yang terjadi.. Kemudian dilakukan analisa Energy Dispersive Spectrometer (EDS) dan didapatkan hasil kandungan karbon untuk selulosa dan lignin lebih tinggi pada bambu petung Indonesia yaitu masing-masing 65,29 wt.\% dan 66,05 wt.\%. Morfologi bambu menunjukkan bahwa serat dan matriks yang ada pada bambu petung Filipina lebih rapat dibanding bambu petung Indonesia. Nilai puncak tertinggi berdasarkan X-Ray Diffraction (XRD) terdapat pada bambu petung Filipina pada $2 \theta$ sebesar 34,49 dan fasa berbentuk kubik.
\end{abstract}

Kata Kunci: Bambu petung, komposit, lignin, selulosa, karakterisasi

\section{Pendahuluan}

Bambu adalah salah satu jenis tanaman yang memiliki kelebihan dalam bidang material teknik (Ardhyananta dkk., 2012). Pada perkembangan material komposit saat ini tidak hanya berasal dari bahan sintetis namun juga dari material alam. Matrik bambu dapat memberikan sifat ketangguhan, kekakuan dan sifat dari bambu sebagai penguat pada komposit polimer. Bambu merupakan salah satu jenis tanaman rumput yang masuk dalam ordo Graminae, familia Bambuseae. Bambu merupakan tumbuhan berumpun, berakar serabut, memiliki batang berbentuk silinder dengan diameter bervariasi dari pangkal 
sampai ujung, sifatnya keras, berongga, dan mempunyai pertumbuhan primer yang cepat tanpa diikuti oleh pertumbuhan sekunder sehingga tingginya dapat mencapai 20 meter (Oka, 2009).

Jenis bambu yang umum digunakan salah satunya adalah dendrocalamus asper atau lebih dikenal dengan bambu petung.

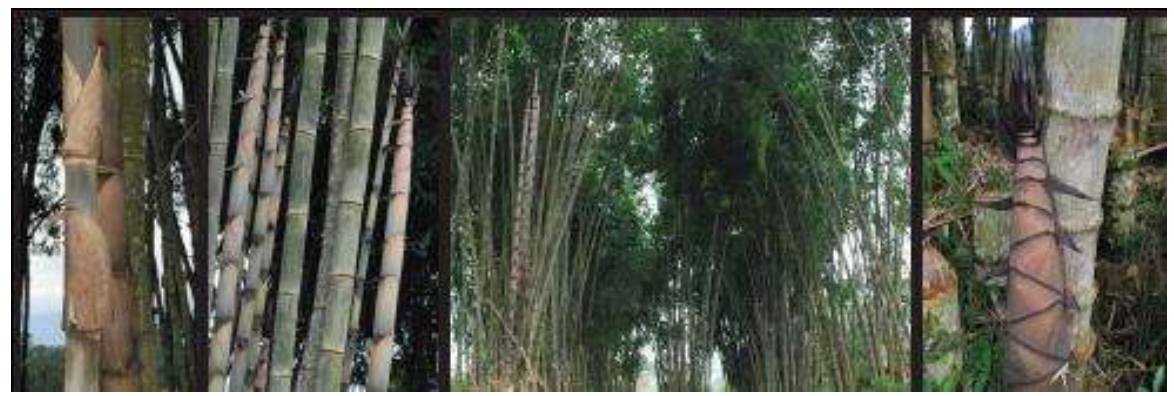

Gambar 1. Bambu Petung

Sumber : Handbook on Erect Bamboo Species Found in the Philippines (2012)

Bambu jenis ini telah banyak dikultivasi dan ditanam sebagai tanaman perkebunan di Thailand, Filipina, dan Indonesia (Malanit, 2009). Bambu ini memiliki diameter yang relatif besar bila dibandingkan bambu jenis lainnya. Sifatnya sangat kuat, dengan jarak ruas pendek yaitu $40-60$ centimeter, diameter mencapai 20 centimeter, tebal 10 - 15 milimeter. Garis tengah bambu petung $80-13$ centimeter, panjang batang $10-20$ meter. Oleh karena itu bambu petung sering ditanam dan digunakan sebagai elemen tekan karena kemampuan menahan tekan yang tinggi (Oka, 2009). Bambu petung merupakan salah satu dari 3 jenis spesies bambu yang paling banyak tersebar di Indonesia (Judawisastra, 2016). Lalu dalam perkembangannya sendiri ada sekitar 65 jenis bambu yang ditemukan di Filipina dari jumlah 1500 spesies bambu yang ada di dunia (Rojo, 1996). Bambu petung di Filipina memiliki manfaat yang besar dalam program lingkungan dan mata pencaharian, karena memiliki manfaat di bidang ekologi, ekonomi dan sosialnya (Bruno, 2017).

Pertumbuhan tidak terlepas dari pengaruh lingkungan sekitar tempat tanaman tersebut tumbuh. Beberapa faktor yang berpengaruh terhadap pertumbuhan bambu adalah jenis tanah dimana tanaman bambu dapat tumbuh yaitu pada tanah yang bereaksi asam dengan $\mathrm{pH}$ sekitar 3,5 dan akan mencapai kondisi optimal pada tanah yang memiliki pH 5,0 sampai 6,5, serta ketinggian tempat yang mana bambu mampu tumbuh dengan baik di dataran rendah maupun tinggi yaitu antara ketinggian $0-2000 \mathrm{~m}$. Kemudian pengaruh iklim berpengaruh terhadap kemampuan tumbuh bambu yaitu curah hujan, dan kelembapan udara. Menurut Sutiyono dkk. (1996) menyebutkan bahwa temperatur udara yang cocok untuk pertumbuhan bambu berkisar antara $8,8^{\circ} \mathrm{C}-36^{\circ} \mathrm{C}$, sedangkan curah hujan minimal sebesar 1.020 $\mathrm{mm} /$ tahun, dan kelembaban udara minimal $80 \%$. Berdasarkan klasifikasi iklim di Indonesia tumbuhan bambu dapat tumbuh pada berbagai tipe iklim mulai dari tipe iklim A, B, C, D, sampai E, atau dari tipe iklim basah hingga kering. Makin basah tipe iklimnya, maka semakin bervariasi jenis bambunya (Sutiyono, dkk., 1996).

Berdasarkan dari penjelasan diatas pertumbuhan bambu petung sangat dipengaruhi oleh keadaan geografis lingkungannya, oleh karena itu dalam penelitian ini berfokus pada perbedaan karakteristik bambu petung di Indonesia dan Filipina serta potensi pada pengembangan material komposit.

\section{Metode}

Metode yang digunakan dalam penelitian ini meliputi preparasi bambu, analisa termal, pengujian DSC dan pengujian karakterisasi dengan metode EDS, SEM, dan XRD.

\subsection{Preparasi Bambu}

Bahan yang digunakan pada penelitian ini adalah bambu petung (Dendrocalamus asper) dari daerah Jember, Jawa Timur, Indonesia dan daerah kota Mandaue, Provinsi Cebu, Filipina. Bagian bambu yang digunakan ialah ruas tengah. Bambu petung dilakukan pemotongan menggunakan mesin pemotong 
(Gambar 2) menjadi spesimen pengujian yang lebih kecil dengan massa yang digunakan sebesar 10 gram. Sebelum dilakukan pengujian karakterisasi material, spesimen dibersihkan menggunakan alkohol lalu dikeringkan menggunakan tisu

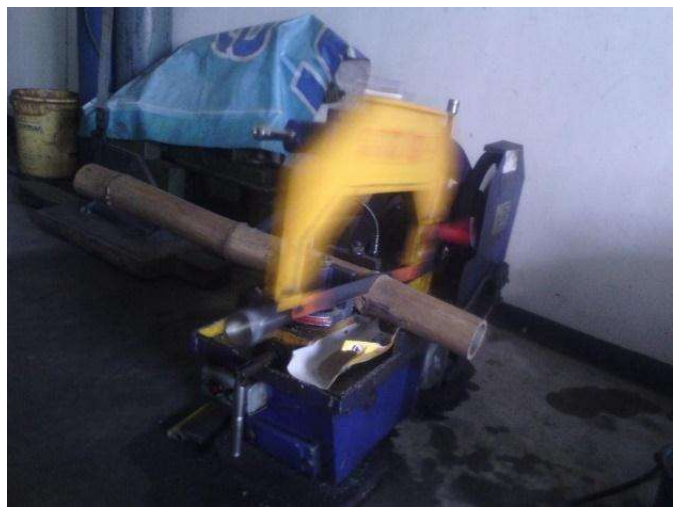

Gambar 2. Pemotongan bambu petung

\subsection{Pengujian DSC (Differential Scanning Calorimetry)}

DSC merupakan suatu teknik pengujian analisa termal untuk mengukur energi yang diserap atau diemisikan oleh sampel menjadi fungsi waktu atau temperatur. Ketika terjadi transisi termal pada sampel, DSC akan memberikan pengukuran kalorimetri dari energi transisi pada temperatur tertentu. Beberapa informasi yang didapatkan dari proses pengujian ini adalah scanning pemanasan yang meliputi temperatur leleh $(\mathrm{Tm})$, yang didapat dari nilai maksimum puncak endotermik dan panas peleburan. Analisa kuantitatif untuk stabilitas termal dari sampel juga diperiksa menggunakan (DSC) dengan TA Instrument DSC Q20.

\subsection{Pengujian Karakterisasi Material}

Berikut ini merupakan beberapa pengujian karakterisasi yang dilakukan untuk mengetahui sifat dari bambu petung Indonesia dan Filipina.

\subsubsection{Energy Dispersive Spectrometer (EDS)}

Merupakan salah satu teknis yang digunakan untuk mengetahui unsur atau karakteristik kimia dari spesimen uji bambu petung di Indonesia dan Filipina. Pada penelitian ini akan dianalisa hasil dari proses EDS berupa perbandingan komposisi senyawa kimia bambu petung pada bagian selulosa dan lignin.

\subsubsection{Scanning Electron Microscopy (SEM)}

Pengujian SEM dilakukan dengan menggunakan alat Pan Analitycal SEM FEI INSPECT S50 yang berada di Laboratorium Karakterisasi Teknik Material dan Metalurgi FTI ITS. SEM merupakan teknik yang dilakukan untuk mengetahui morfologi dari spesimen uji. Prinsip kerja SEM menggunakan sinyal yang dihasilkan oleh elektron yang dipantulkan atau seberkas elektron sekunder. Sampel dari kedua jenis bambu petung terlebih dahulu dilakukan coating agar sampel bersifat konduktor elektron. Coating atau pelapisan dalam pengujian SEM pada penelitian ini menggunakan platina $(\mathrm{Pt})$.

\subsubsection{X-Ray Diffraction (XRD)}

Pengujian XRD dengan menggunakan alat XRD PW 3040/60 X'Pert PRO Instrumen Enclosure yang berada di Laboratorium Karakterisasi Teknik Material dan Metalurgi FTI-ITS. Pengujian ini dilakukan untuk mengidentifikasi unsur atau senyawa (analisis kualitatif) dan penentuan komposisi (analisis kuantitatif). Pengujian XRD pada penelitian ini adalah untuk menganalisis struktur, senyawa dan fasa yang terbentuk dari bambu petung Indonesia dan Filipina. Pengujian XRD pada penelitian ini spesimen pengujian digunakan sebesar $10 \mathrm{mg}$ dengan ketebalan $1 \mathrm{~mm}$.

\section{Hasil dan Pembahasan}

Pembahasan pada penelitian ini memuat analisa pengujian termal pada bambu petung Indonesia dan Filipina. Hasil uji karakterirasi pada pengujian didapatkan kadar karbon dan oksigen pada kedua bambu 
petung, morfologi bambu petung pada lignin dan selulosa sebagai matrik dan serat serta analisa fasa yang terbentuk pada XRD.

\subsection{Pengujian DSC ( Differential Scanning Calorimetry)}

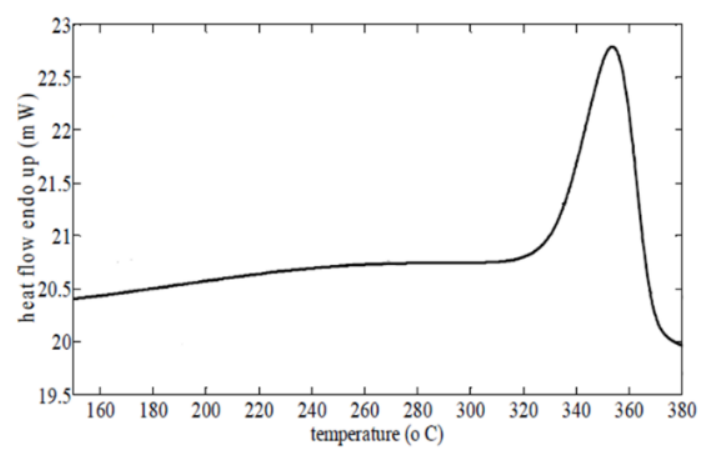

(a)

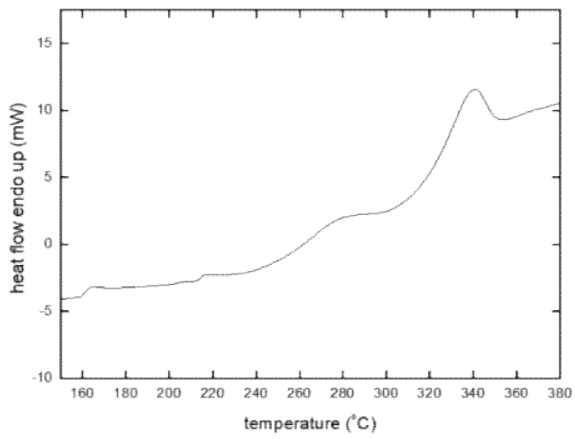

(b)

Gambar 3. Termogram DSC Selulosa (a) bambu petung Indonesia (Wida dkk., 2017) dan (b) bambu petung Filipina

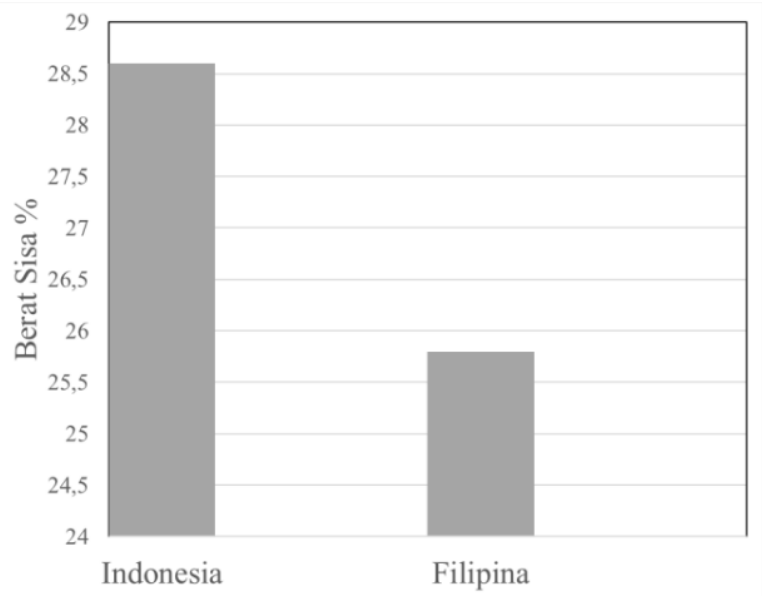

Gambar 4. Analisis termal bambu petung Indonesia dan bambu petung Filipina

Hasil pengujian DSC pada Gambar 3(a) menunjukkan bahwa titik leleh selulosa pada bambu petung Indonesia mencapai $354,34^{\circ} \mathrm{C}$ yang mana temperature tersebut menunjukkan titik temperatur puncak kristalisasi. Lalu pada gambar 3(b) menunjukkan bahwa dari pengujian pada sampel bambu petung Filipina memiliki titik leleh paling tinggi pada reaksi endotermik sebesar $341^{\circ} \mathrm{C}$ dimana peak ini menunjukkan titik Tp (puncak kristalinitas) lalu pada peak paling rendah menunjukkan temperatur transisi dan pada peak selanjutnya menunjukkan temperature awal kristalisasi (Tg) sebelum akhirnya mencapai puncak kristalisasi (Tp). Pada kedua sampel bambu tersebut menunjukkan puncak kritalinitas berbeda yang mengindikasikan bahwa sampel tersebut terjadi vibrasi sehingga mengakibatkan dekomposisi atau pemutusan ikatan antar rantai terhadap ketahanan panas yang rendah dan terbentuk titik leleh. Terjadinya perbedaan titik leleh dimungkinkan karena perbedaan pada struktur selulosa antara bambu petung Indonesia dan bambu petung Filipina. Analisa ini dapat didukung dengan pengujian morfologi SEM yang akan dibahas di subbab selanjutnya.

Gambar 4 menunjukkan pengaruh bambu petung dari Indonesia dan Filipina terhadap pembentukan karbon hitam pada temperatur pemanasan $800^{\circ} \mathrm{C}$. Terjadi perbedaan yang signifikan dimana berat sisa pada bambu petung Indonesia ialah $28,6 \%$ sedangkan berat sisa pada bambu petung Filipina ialah $25,79 \%$. Sebelum proses karbonisasi, bambu petung Filipina memiliki kadar oksigen yang lebih tinggi baik dari lignin maupun selulosa (Tabel 1). Saat proses karbonisasi, pelepasan oksigen terjadi semakin 
banyak sehingga terjadi pengurangan massa berlebih pada bambu petung Filipina. Disamping itu, pengurangan massa dapat terjadi karena kandungan air pada bambu petung. Dari hasil analisa termal, dapat dikatakan bahwa kadar air pada bambu petung Filipina memiliki kadar lebih banyak. Bambu merupakan material yang bersifat higroskopis yang dipengaruhi kelembaban udara sekitarnya. Kadar air akan berpengaruh terhadap kekuatan bambu, semakin kecil kadar air kekuatan bambu akan bertambah dan juga sebaliknya (Oka, 2009).

\subsection{Pengujian Energy Dispersive Spectrometer (EDS)}

Tabel 1. Komposisi senyawa kimia bambu petung Indonesia dan Filipina

\begin{tabular}{|c|c|c|c|c|}
\hline \multirow{2}{*}{ Position } & \multirow{2}{*}{ Material } & \multirow{2}{*}{ Element } & \multicolumn{2}{|c|}{ Average } \\
\hline & & & wt(\%) & $\operatorname{at}(\%)$ \\
\hline \multirow{4}{*}{ Indonesia } & \multirow[t]{2}{*}{ Lignin } & $\mathrm{C}$ & 58,54 & 65,29 \\
\hline & & $\mathrm{O}$ & 41,46 & 34,71 \\
\hline & \multirow{2}{*}{ Selulosa } & $\mathrm{C}$ & 59,36 & 66,05 \\
\hline & & $\mathrm{O}$ & 40,64 & 33,95 \\
\hline \multirow{4}{*}{ Filipina } & \multirow{2}{*}{ Lignin } & $\mathrm{C}$ & 55,53 & 62,45 \\
\hline & & $\mathrm{O}$ & 44,47 & 37,55 \\
\hline & \multirow{2}{*}{ Selusosa } & $\mathrm{C}$ & 57,28 & 64,11 \\
\hline & & $\mathrm{O}$ & 42,72 & 35,89 \\
\hline
\end{tabular}
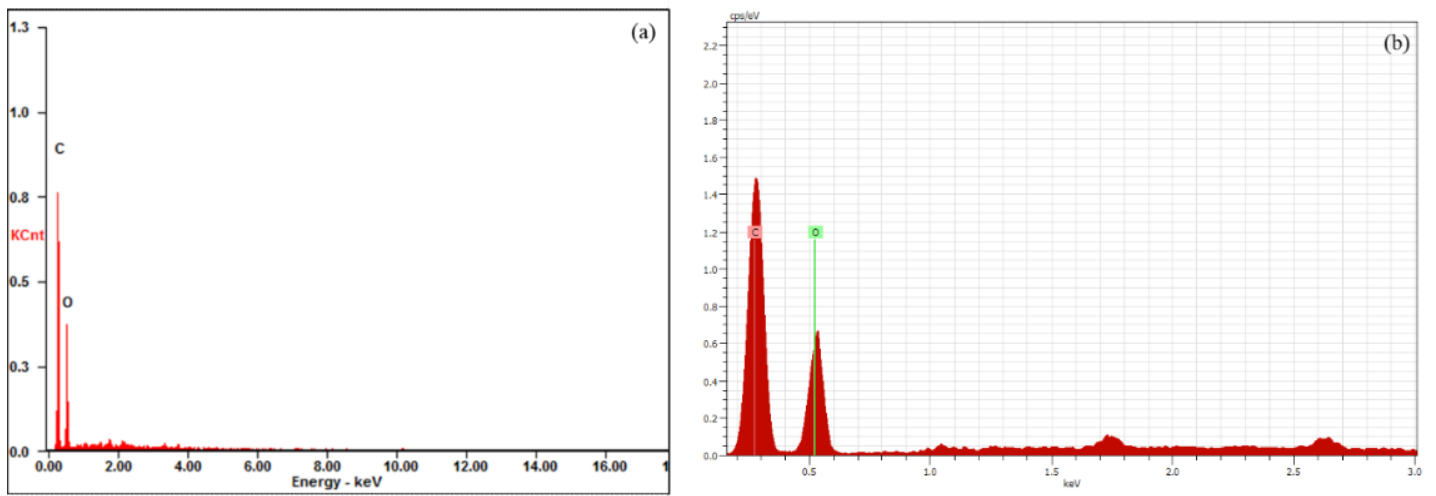

Gambar 5. Grafik SEM-EDS yang menunjukkan unsur-unsur yang terkandung pada (a) bambu petung Indonesia dan (b) bambu petung Filipina

Komposisi senyawa kimia bambu petung ditunjukkan pada Tabel 1. Pengujian tersebut dilakukan pada kedua bambu petung yang ada di Indonesia dan Filipina pada ruas bambu bagian tengah. Pengujian material yang dilakukan terdiri dari selulosa dan lignin bambu petung. Pada lignin bambu petung Indonesia terdapat kadar karbon yang lebih tinggi dan oksigen yang lebih rendah dibandingkan dengan kadar lignin bambu petung di Filipina yaitu 65,29 at.\% dan 34,71 at.\%. Pada pengujian ini didapatkan selulosa pada bambu petung Filipina posisi tengah memiliki kadar karbon yang tinggi, namun masih lebih rendah dibanding Indonesia yang sebesar 66,05 at.\% sedangkan kadar oksigen pada bambu petung Filipina yaitu sebesar 35,89 at.\%. Lalu hasil dari pengujian SEM-EDS (Gambar 5) pada bambu petung Filipina dan Indonesia unsur paling dominan yaitu karbon ditujukkan dari peak tertinggi oleh unsur C. 


\subsection{Hasil Pengujian SEM}

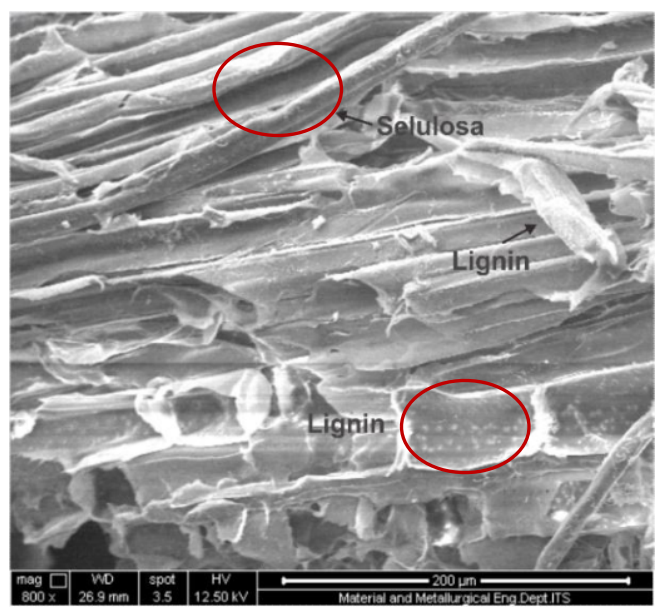

(a)

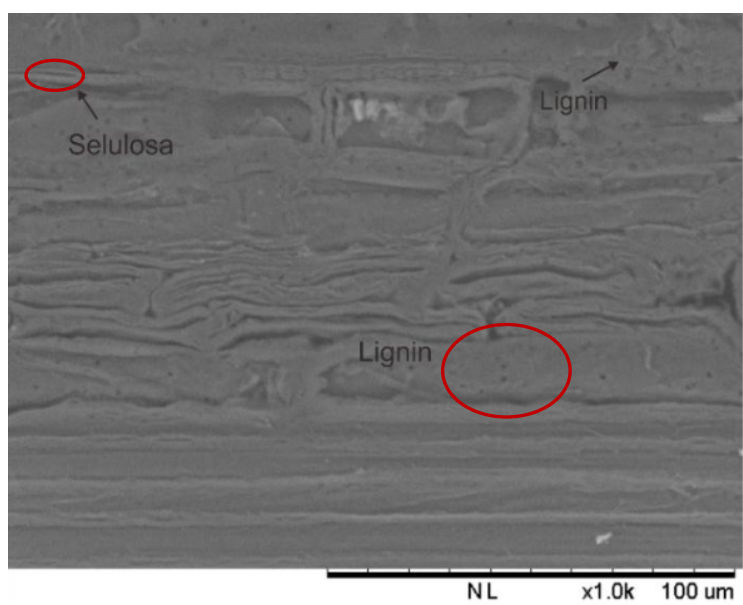

(b)

Gambar 6. Hasil Pengujian SEM bambu petung Indonesia (a) perbesaran 800x dan bambu petung

Filipina (b) perbesaran 1000x

Pada umumnya pohon bambu memiliki lignin $\left[\left(\mathrm{C}_{9} \mathrm{H}_{10} \mathrm{O}_{2}\left(\mathrm{OCH}_{3}\right)_{n}\right]\right.$ dan selulosa $\left(\mathrm{C}_{6} \mathrm{H}_{10} \mathrm{O}_{5}\right)_{\mathrm{n}}$. Lignin pada bambu yaitu matriks sedangkan selulosa pada bambu yaitu serat. Pada Gambar 6, bambu petung menunjukkan arah serat. Arah serat menunjukkan bahwa bambu memiliki arah serat yang homogen. Arah serat unidireksional ini menyebabkan bambu memiliki kekuatan ke arah serat bambu. Pada morfologi Gambar 6(a) terlihat serat yang searah dimana hal tersebut menunjukkan bahwa bambu memiliki arah yang kontinyu dan homogen berbentuk panjang dan silinder. Pada matriks terlihat tidak teratur dan berbentuk cube. Sedangkan pada Gambar 6(b) terlihat serat searah berbentuk silinder dan teratur. Sedangkan pada matriks menunjukkan adanya pori-pori yang muncul serta matriks dan seratnya lebih rapat dibandingkan dengan matriks dan serat pada Gambar 6(a).

\subsection{Hasil Pengujian XRD}
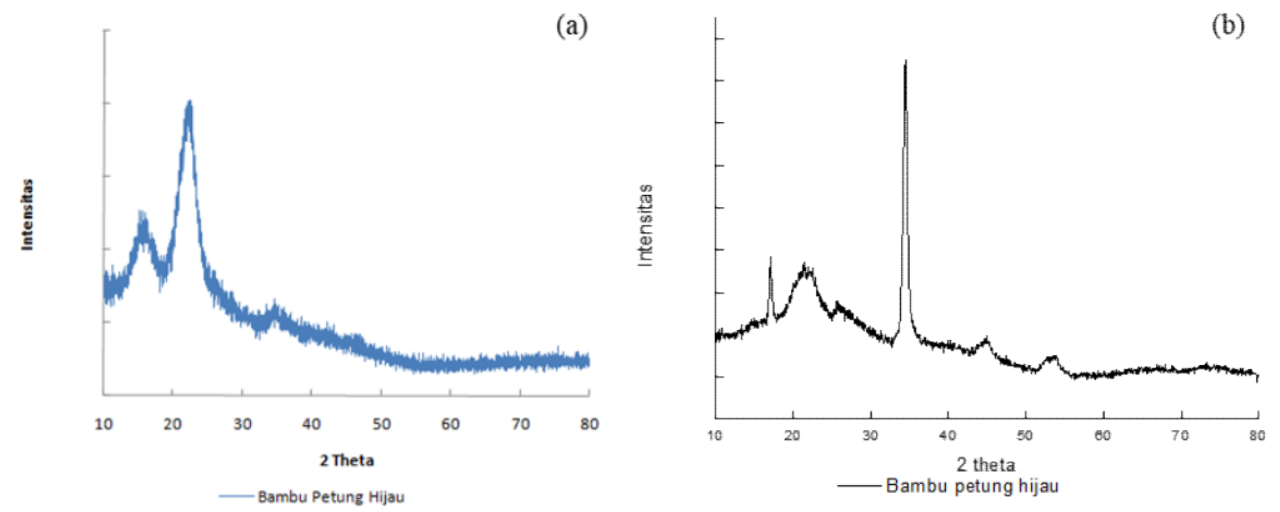

Gambar 7. Hasil uji XRD pada (a) bambu petung Indonesia dan (b) bambu petung Filipina

Dari analisa uji XRD, Gambar 7(a) menunjukkan nilai peak tertinggi pada sudut $2 \theta$ sebesar 22,25 dan diidentifikasi terdapat senyawa karbon dioksida $\left(\mathrm{CO}_{2}\right)$ sesuai dengan kartu JCPDS nomor 73-2058 9 (Puspita dan Ardhyananta, 2013), dimana fasanya adalah kubik dan pola difraksi pada bambu petung Indonesia menunjukkan orientasi kristal. Sedangkan pada Gambar 7(b) memiliki peak tertinggi sebesar 34,49 serta berbentuk tajam karena peningkatan temperature meningkat dengan tajam menyesuaikan dari temperatur acuan dan terdapat senyawa karbon dioksida $\left(\mathrm{CO}_{2}\right)$ dimana fasanya juga berbentuk kubik. Pada puncak sekitar $17^{\circ}$ dan $22^{\circ}$ dengan struktur selulosa sesuai dengan nomor kartu JCPDS 50- 
Pengaruh Faktor Geografi Terhadap Karakteristik Bambu Petung

2184 dengan orientasi kristal selulosa. Puncak tertinggi dari tiga posisi adalah pada 2 theta sekitar $35^{\circ}$ menurut kartu nomor 73-2058 JCPDS, diketahui bahwa ada senyawa karbon dioksida.

\section{Kesimpulan}

Berdasarkan hasil uji DSC dan karakterisasi pada kedua bambu petung menunjukkan sifat yang berbeda yaitu titik leleh pada kedua bambu petung sebesar $354,34^{\circ} \mathrm{C}$ dan $341^{\circ} \mathrm{C}$. Titik leleh pada bambu petung Filipina lebih rendah dikarenakan pembakaran pada bambu Filipina lebih cepat dan efisien namun kandungan lignin dan selulosa pada hasil komposisi senyawa menunjukkan bambu petung Indonesia memiliki kadar karbon yang lebih tinggi sehingga mampu memberikan nilai kalor yang lebih baik. Dari perbedaan titik leleh yang dihasilkan dapat diketahui proses dan penyimpanan termal yang harus dihindarkan pada temperatur leleh pada kisaran tersebut. Pengembangan bambu petung sebagai bahan baku komposit dimana kandungan lignin dan selulosa yang tinggi akan memberikan nilai ketangguhan dan kekuatan tarik yang tinggi. Bambu menunjukkan morfologi serat dan matriks, pada bambu petung Filipina memiliki serat yang rapat dan teratur sehingga batang bambu menjadi lebih kuat pada arah serat dan fasa yang terbentuk pada kedua bambu petung adalah kubik. Nilai peak dan intesitas tertinggi pada hasil pengujian XRD terdapat pada bambu petung Filipina sebesar 34,49, sedangkan pada bambu petung Indonesia sebesar 22,25. Sehingga dapat disimpulkan bahwa faktor geografi dari bambu petung Indonesia dan Filipina berpengaruh terhadap sifat mekanik yang terbentuk sehingga diharapkan dari hasil pengujian ini bisa digunakan pada penelitian selanjutnya.

\section{Ucapan Terima Kasih}

Ucapan terima kasih kami ucapkan kepada laboratorium karakterisasi teknik material dan metalurgi ITS dan laboratorium electronic packaging and green materials NTUST Taiwan yang telah memberikan kesempatan dan dukungan selama pelaksanaan penelitian.

\section{References}

A.G. Toledo-Bruno, R. M. (2017). Ecology of litterfall production of giant bamboo Dendrocalamus asper in a watershed area. Global J. Environ. Sci. Manage, 363-372.

Christina A.R. (2012). Handbook on Erect Bamboo Species Found in the Philippines. Ecosystems Research and Development Bureau, Department of Environment and Natural Resources, College, Laguna

E.I. Puspita dan H. Ardhyananta. (2013). Pengaruh Temperatur Pemanasan terhadap Sintesis Karbon Hitam dari Bambu Ori (Bambusa Arundinacea) dan Bambu Petung (Deondracalamus Asper). Jurnal Teknik Pomits, Vol. 2 No.1 Hal. 2337-3539.

G.M, O. (2009). Kajian Koperatif Lokasi Tumbuh Terhadap Properties Bambu . Palu: Majalah Ilmiah Mektek, Jurusan Teknik Sipil Fakultas Teknik Universitas Tadulako.

Hermawan Judawisastra, U. A. (2016). Karakteristik Sifat Tarik Serat Bambu Petung (Dendrocalamus asper). Bandung: Program Studi Teknik Material, Fakultas Teknik Mesin dan Dirgantara, Institut Teknologi Bandung, Bandung, Indonesia.

Hosta Ardhyananta, Sulistijono, Gala Heri Susilo. (2012). Karakterisasi dan Sifat Mekanik Bambu Ori dan Bambu Petung. Seminar Pascasarjana XII. Surabaya: Institut Teknologi Sepuluh Nopember.

Kusumaningrum, W. B., Rochmadi, dan Subyakto (2017). Pembuatan Selulosa Terasetilasi dari Pulp Bambu Betung (Dendrocalamus asper) serta Pengaruhnya Terhadap Sifat Mekanis Biokomposit Polipropilena. Website : http://ejournal.undip.ac.id/index.php/reaktor/

P., M. (2009). The Suitability of Dendrocalamus asper Backer for Oriented Strand Lumber [Diserrtation]. Hamburg: Department of Biology, Faculty of Mathematics, Informatics and Natural Sciences University of Hamburg.

Rojo, J. P. (1996). Bamboo resources of the Philippines. First National Conference of Bamboo. Iloilo Sarabio Manor .

Sutiyono, Hendromono, Marfu'ah, Ihak. (1996). Teknik Budidaya Tanaman Bambu. Pusat Litbang Hasil Hutan, Bogor 